\title{
NEW METHOD OF PROPORTIONAL COUNTER FEEDBACK BIASING FOR WIDE-RANGE RADIATION DOSE-RATE MONITOR
}

\author{
M. K. Kopp, K. H. Valentine, G. C. Guerrant, and F.W. Manning \\ Instrumentation and Controls Division \\ Oak Ridge National Laboratory \\ Oak Ridge, Tennessee 37831, USA.
}

\begin{abstract}
DFSCLAIMER
This report was prepared as an account of work sponsored by an agency of the United States Government. Neither the United States Government nor any agency thereof, nor any of their employees, makes any warranty, express or implied, or assumes any legal liability or responsibility for the accuracy, completeness, or usefulness of any information, apparatus, product, or process disclosed, or represents that its use would not infringz privately owned rights. Reference herein to any specific commercial product, process, or service by trade name, trademark, manufacturer, or otherwise does not necessarily constitute or imply its endorsement, recommendation, or favoring by the United States Government or any agency thereof. The views and opinions of authors expressed herein do not necessarily state or reflect those of the United States Government or any agency thereof.
\end{abstract}

\footnotetext{
*Research sponsored by the Federal Emergency Management Agency under interagency agreement 40-1086-80 with the U. S. Department of Energy under contract DE-ACO5-840R21400 with Martin Marietta Energy Systems, Inc..
} 
NEW METHOD OF PROPORTIONAL COUNTER FEEDEACK BIASING

FOA WIDE-RANGE RADIATION DOSE-RATE MONITORS*

M. K. Kopp, K. H. Valentine, G. C. Guerrant, and F. W. Manning

Instrumentation and Controls Division

Oak Ridge National Laboratory

Oak Ridge, Tennessee 37831, USA

\section{Abstract}

A prototypic wide-range radiation dose-rate monitor for clvil defense applications has been developed and tested. The specifled dose-rate range ( 0 to 500 $\mathrm{R} / \mathrm{h}$ ) was displayed on a single readout scale by using feedback-controlled biasing of a proportional counter. This new method is based on controlling the avalanche multiplication factor (gas gain) of the counter by varying its bias voltage in response to its measured output current (1.e., detected dose rate). The counter output current varies between 0 and $1.5 \mathrm{nA}$ in a quas1logarithic response to dose rates between 0 and $500 \mathrm{R} / \mathrm{h}$. The corresponding values of gas gain and bias voltage range from 1 to 300 and 200 to $1900 \mathrm{~V}$ respect 1 vely.

\section{Introduction}

A method of feedback-controlled blasing of proportional counters was cieveloped and tested in a widerange dose-rate monitor for civil defense applicacions. Proportional counters are a good alternative to Gelger Mueller counters for this application because, in conjunction with feedback-controlled blasing, they offer w1der range capabilitles and a longer life expectancy.

The main purpose of this research was to investigate the properties of feedback-controlled biasing in connection with a program almed at developing a portable monitor with a nonsaturable, monotonlc response and capable of measuring exposure rates in the range 0 to $>1 \mathrm{kR} / \mathrm{h}$ on a single scale that does not require switching.

* Research sponsored by the Federal Emergency Management Agency under Interagency Agreement 40-1086-80 with thn U.S. Department of Energy under Contract DE-AC05-840R21400 w1th Martin Marletta Energy Systems, Inc.
Feedback-Controlled Biasing

of Proportional Counters

To extend the range capability of a dose-rate monitor with a gas proportional counter, the output current of the counter is used in a feedback circuit to control 1 ts own bias voltage (Fig. 1). For a small detected dose rate, the blas roltage--and, consequent$1 y$, the counter gas gain--are at their maximum values; that 1s, the counter operates at its highest sensitivity. As the detected dose rate increases, the bias voltage and gas gain decrease, thereby reducing detection sensitivity.

This dose-rate-dependent sensitivity characteristic results in a compression of the readout scale and extends the dynamic range of the proportional counter from pulse counting at background radiation levels to Ionization current measurements at dose-rate levels up to $1 \mathrm{kR} / \mathrm{h}$. Also, the proportional counter life expectancy is greatly extended by operating it at low values of gas gain ( $<1)$ during $h 1 g h$ exposure rates $(>500 \mathrm{k} / \mathrm{h})$.

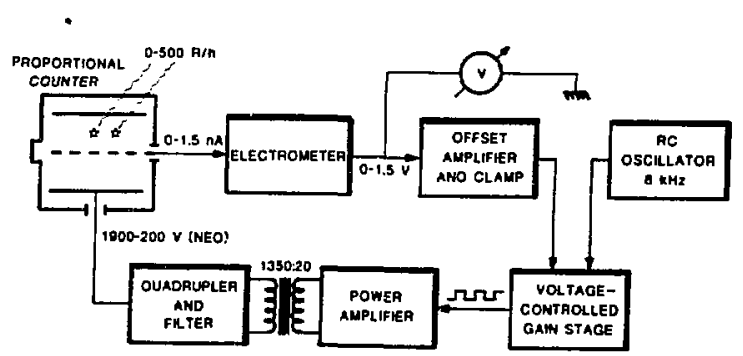

Fig. 1. A detected dose rate ranging from 0 to $500 \mathrm{R} / \mathrm{h}$ generates an ionization current in the proportional counter ( 0 to $1.5 \mathrm{nA}$ ) that drives the readout meter $v$ ( 0 to $1.5 \mathrm{~V}$ ) and controls the detector blas voltage in the range 1.9 to $0.2 \mathrm{kV}$. 
For the prototypic monitor, we measured functional relationships between dose rate, Ionization cirrent, gas gain, and bias voltage (Figs. 2 and 3) 2.3 follows:

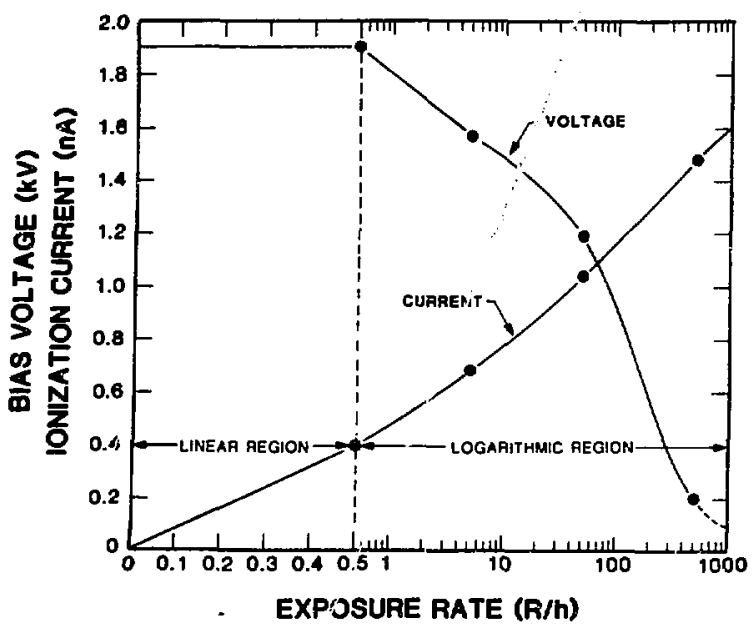

Fig. 2. The lonization current of the proportional counter varies linea:ly from 0 to $0.4 \mathrm{nA}$ and quasilogarithmically fron 0.4 to $1.5 \mathrm{nA}^{\prime}$ in response to exposure-rate variations from 0 to $0.5 \mathrm{R} / \mathrm{h}$ and 0.5 to $500 \mathrm{R} / \mathrm{h}$ respectively. The blas voltage is held constant at $1.9 \mathrm{kV}$ in the 1 inear range and decreases under feedback control from 1.9 to $0.2 \mathrm{kV}$ in the logaritinm se range of the exposure-rate scale.

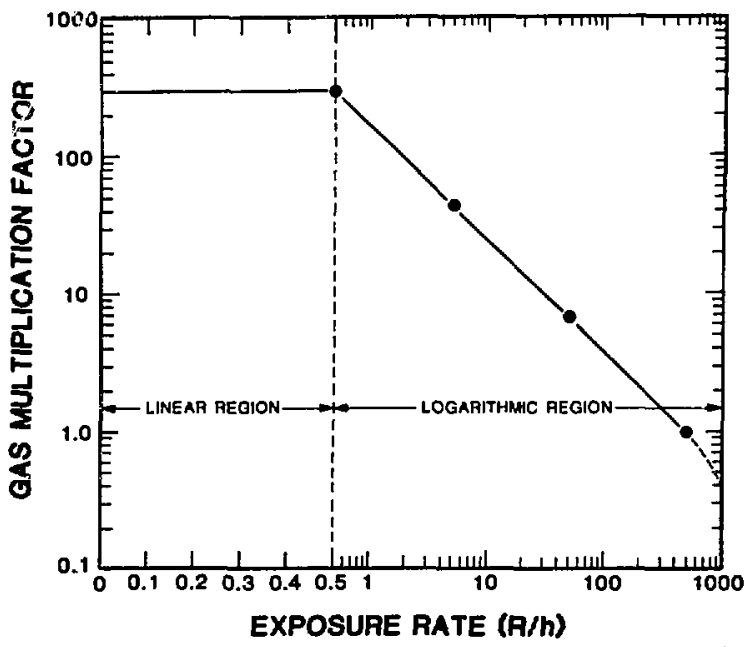

Fig. 3. The gas multiplication factor is held constant at 300 in the linear region and follows the decrease in bias voltage (Fig. 2) from 300 to 1 in the logarithmic region of the exposure-rate scale.
In response to an increase in dose rate from 0 to $0.5 \mathrm{R} / \mathrm{h}$, the lonization current increases inearly from 0 to $0.4 \mathrm{nh}$ while the blas voltage and the gas gain are held constant by the clamp c1rcult at $1.9 \mathrm{kV}$ and 300 respectively. For a detected dose rate increase from 0.5 to $500 \mathrm{R} / \mathrm{h}$, the Ionization current Increases in a quasi-logarithmic mode from 0.4 to $1.5 \mathrm{nA}$, the blas voltage decreases from 1.9 to $0.2 \mathrm{kV}$, and the gas gain decreases from 300 to 1 . Beyond $500 \mathrm{R} / \mathrm{h}$ the response is highly compressed; that 1s, as the lonization current approaches 1.7 il for large values of detected dose rate ( $>1 \mathrm{kR} / \mathrm{h}$ ), the bias voltage (and therefore the gas gain) approach zero. Consequently, the response of this monitor neither saturates nor exhibits foldback.

\section{Proportional Counter}

The proportional counter was fllled with $90 \mathrm{mg}$ of $80 \% \mathrm{Ar}+20 \mathrm{CF}_{4}$ at atmospheric pressure to dellver an ionization current of $1.5 \mathrm{nA}$ at unity gas gain when exposed to a $500-\mathrm{R} / \mathrm{h}$ gamma radiation fleld. ${ }^{1}$ We did not expect this gas mixture to have an alr-equivalent response below $100 \mathrm{kev}$, but 1ts dielectric properties made it a pood cholce for the proof-of-principle monitor. A gas envelope with 3-mom-thick aluminum walls was used for compensation to make the response nearly air equivalent for gamma energies between 0.1 and 2 MeV. 2

The active counter gas volume is a $40-\mathrm{mm}-\mathrm{h} 1 \mathrm{gh}$, 40-mm-diam cylinder. The anode wire (25- $\mu$ m-dian stainless steel) and the envelope are operated at ground potential, while the cathode cylinder is operated at negative blas voltage. This arrangement has two advantages: The ionization current can be measured with a grsund-referenced electrometer ccnnected to the anode, and the envelope is a guard structure that mitigates leakage-current effects across the anode insulators. The gas multiplication factor ranges from 0 to $6 \times 10^{3}$ in response to anode-to-cathode blasing between 0 and $2.5 \mathrm{kV}$; no breakdown or spurlous pulses were observed in this range.

\section{Electronic Circuit}

The measurement and control functions of the electronic clrcuits are generated by two integrated circuits (TLO94 and CA3053) and one transistor (2N5089) for the high-voltage transformer drive. The readout used for the prototypic monitor is a 50- $4 \mathrm{~A}$ panel meter (FIB. 1). The circuit is powered by a $6-V$ battery and consumes $72 \mathrm{mw}$. 
The four amplifier sections of the TLO94 Quad amplifier are used as follows:

- The first section is used as an electrometer of $10^{9}-a$ transresistance; its output drives the 50- $\mu \mathrm{A}$ panel meter.

- The second section 13 used as a voltage-gain and offset amplifier stage; its output voltage controls the gain of the CA3053 amplifier stage.

- The third section is an 8-kHz RC oscillator; its output is connected to the voltage-controlled gain stage for amplitude modulation.

- The fourth section of the TLOS4 and the 2 N5089 transistor are used as a power amplifier to drive the primary of the high-voltage transformer.

The dc-bias voltage at the output of the highvoltage quadrupler ranges between 0.2 and $1.9 \mathrm{kV}$ in response to an electrometer input current ranging from 1.5 to $0.4 \mathrm{nA}$.

\section{Experimental Results}

The prototypic dose-rate monitor was calibrated at exposure levels of $0.4,4.0,40$, and $400 \mathrm{R} / \mathrm{h}$ using a $137 \mathrm{Cs}$ source. The time constant of the response to a step function change in exposure rate was $f g$ in the range 0.4 to $400 \mathrm{R} / \mathrm{h}$. The energy response curve was measured at the facilities of the Federal Emergency Management Agency and showed a strong peak in the range 30 to $60 \mathrm{keV}$ as compared to an air-pilled Ionization chamber. More uniform energy response w1ll be obtained in future designs by using more nearly air-equivalent gas mixtures. Preliminary tests with $\mathrm{Ne}-\mathrm{CH}_{4}$ show promising results.

\section{Discussion}

Preliminary data obtained with the prototypic wide-range radiation dose-rate monitor indicate that the feedback-controlled blasing of proportloral counters is a pracilical wethod for monitoring exposure rates from background levels up to $1 \mathrm{kF} / \mathrm{h}$. These data provide an adequate basis for the design of an cngi- neering model of such a monitor and indicate several modifications that should be incorporated into an Instrument for fallout shelter applications:

- To measure low-level exposure rates between 0 and $1 \mathrm{R} / \mathrm{h}$ with reater accuracy, a 6-digit LCD readout, calibrated directly in $\mu R / h$ and gated by a io-s clock, w1ll be incorporated.

- To facilitate interpretation of the exposure rate in an emergency situation, an indicator of increasing or decreasing exposure rate will be provided, and a bar-graph LCD will replace the panel meter readout.

- To make the response to exposure rate nearly air equivalent, gas mixtures containing a higil concentration of neon will be used.

- To reduce the power requirements, low-current ampl1fiers will be used; In addition, neon requires lower exitation voltages than argon, which further reduces the power requirements.

With these modifications, a wide-range dose-rate monitor is feasible for operation as a fallout shelter instrument for the measurement of exposure rates ranging from background zevels to $1 \mathrm{kR} / \mathrm{h}$. The use of the feedback biasing method of the proportional counter provides a rugged instrument with long iffe expectancy. In addition, sensitivity and scale conf gurations for special-purpose instruments are easily achlered by selecting appropriate ranges of gas gain (from 0 to $10^{4}$ ) and feedback circult transfer functions.

\section{Acknowledgments}

The authors gratefully acknowledge the assistance of v. C. Miller of Oak Ridge National Laboratory and the support of $C$. R. Siebentritt of the Federal Emergency Management Agency and L. C. Oakes of Oak R1dge National Laboratory.

\section{References}

1. G. F. Knoll, Radiation Detection and Measurewent, John Wiley and Sons, New York, 1979, p. 168.

2. Ibid., p. 167. 